\title{
Planejamento, desenvolvimento e os gastos em educação em Santa Catarina (1955-2010) ${ }^{1}$
}

\section{Resumo}

Liara Darabas Ronçani*

Esta pesquisa tem como objetivo apresentar e analisar a trajetória de gastos do governo do Estado de Santa Catarina com educação no período compreendido entre 1955 e 2010. São apresentados os gastos por funções, subfunções, órgãos e categorias econômicas, além do percentual empregado na manutenção e desenvolvimento do ensino, segundo as vinculações constitucionais de recursos. Analisa-se ainda, a relação entre a trajetória de gastos com educação e as metas estabelecidas nos planos de governo catarinenses. As fontes analisadas foram os relatórios de Prestações de Contas do Governo do Estado (TCE-SC), Anuários Estatísticos do Brasil (IBGE), planos estaduais de governo, e as principais leis e decretos relacionados a normatização da educação no Brasil e em Santa Catarina. Através da pesquisa verificou-se que a média de gastos do governo estadual catarinense com educação no período analisado ficou em torno de $18 \%$ do total de gastos realizados, chegando em alguns períodos a compreender até $26 \%$ da despesa total realizada. No entanto, apesar de o Estado gastar parte expressiva do seu orçamento com a função educação, os problemas educacionais e socioeconômicos têm persistido ao longo tempo. É necessário compreender que a expansão do gasto público em educação é apenas um dos elementos que contribuem para o desenvolvimento socioeconômico.

Palavras-chave: gastos públicos; Santa Catarina; Educação.

\section{Plannning, development and spending on education in Santa Catarina} (1955-2010)

\begin{abstract}
The objective of this research is to present and analyze the expenditure trajectory of the government of the State of Santa Catarina with education in the period between 1955 and 2010. The expenditures by functions, subfunctions, agencies and economic categories are presented, in addition to the percentage used in maintenance and development of education, according to the constitutional linkages of resources. We also analyze the relation of the educational expenses trajectory with the goals established in the Santa Catarina government plans. The analyzed sources were: Reports of State Government Accounts Payments (TCE-SC); Statistical Yearbooks of Brazil (IBGE); state government plans; and the main laws and decrees related to the normalization of education in Brazil and Santa Catarina. Through the research it was verified that the average expenses of the state government of Santa Catarina with education in the analyzed period was around $18 \%$ of the total expenses incurred, arriving in some periods to comprise up to $26 \%$ of the total expenses incurred. However, despite the fact that the State spent a significant part of its budget on the education function, educational and socioeconomic problems have persisted over time. It is therefore necessary to understand that the expansion of public spending on education is only one element that contributes to socioeconomic development.
\end{abstract}

Keywords: public expenditure; Santa Catarina; education.

JEL: I2, I28

\footnotetext{
${ }^{1}$ Neste artigo apresento parte dos resultados de minha dissertação de mestrado, defendida em 2017, sob orientação do professor Alcides Goularti Filho, junto ao Programa de Pós-Graduação em Desenvolvimento Socioeconômico (PPGDS), da Universidade do Extremo Sul Catarinense (UNESC).
} 
* Mestre em Desenvolvimento Socioeconômico pela Universidade do Extremo Sul Catarinense (UNESC). E-mail: liadarabas@hotmail.com

\section{Introdução}

Esta pesquisa tem como objetivo apresentar e analisar a trajetória de gastos do governo do Estado de Santa Catarina, com educação no período compreendido entre 1955 e 2010. São apresentados e analisados os gastos por funções, subfunções, órgãos e categorias econômicas, além do percentual empregado na manutenção e desenvolvimento do ensino, segundo as vinculações constitucionais de recursos. Pretende-se ainda, analisar a relação entre a trajetória de gastos com educação e as metas estabelecidas nos planos de governo catarinenses. Assim como, analisam-se as concepções gerais dos planos de desenvolvimento e a participação setorial da educação em cada um dos planos de governo catarinenses, desde 1955, ano em que foi elaborado o Plano de Obras e Equipamentos (POE), primeira aproximação ao planejamento estadual catarinense, até o Plano 15 II: A Mudança Continua (2007-2010), o último plano de governo do período analisado.

Para cumprir com os objetivos propostos foram analisados os seguintes documentos: relatórios de Prestações de Contas do Governo do Estado, encontrados na biblioteca do Tribunal de Contas do Estado Santa Catarina (TCE-SC) e no Centro de Memória da Assembleia Legislativa do Estado de Santa Catarina (ALESC); os Anuários Estatísticos do Brasil, publicados pelo Instituto Brasileiro de Geografia e Estatística (IBGE); os planos estaduais de governo e os Planos Estaduais de Educação (PEEs), que estão disponíveis no Arquivo Público do Estado de Santa Catarina e na Biblioteca da Secretaria Estadual de Educação; e as principais leis e decretos relacionados à normatização da educação no Brasil e em Santa Catarina durante o período analisado.

Entre as principais ações do Estado que nortearam os rumos da educação brasileira no período que vai de 1955 até 2010 encontram-se a Lei de Diretrizes de Bases da Educação (1961), a Reforma Universitária (Lei n ${ }^{\circ}$ 5.540/1968), a Reforma de $1^{\text {o e }} 2^{\circ}$ graus (Lei n ${ }^{\circ}$ 5.692/1971), e, a segunda Lei de Diretrizes de Bases da Educação (1996), além das Constituições. No Brasil, a ideia de planejar o desenvolvimento econômico nacional iniciou-se em meados da década de 1940. Com o Plano de Metas, de Juscelino Kubistchek, efetiva-se o planejamento econômico nacional global, por meio do qual, o projeto de desenvolvimento econômico brasileiro lançou as bases para a 
Revista Catarinense de Economia - RCE

APEC - Associação dos Pesquisadores em Economia Catarinense

10 Semestre de 2018 - www.apec.pro.br/rce

modernização da estrutura econômica capitalista. Para a implantação desse projeto também era considerada fundamental a modernização da educação, para que a formação da força de trabalho acompanhasse os objetivos de desenvolvimento do país. A associação que passou a ser estabelecida entre planejamento, desenvolvimento econômico, educação e modernização, a partir do Plano de Metas, influenciou os estados da federação a elaborarem também seus planos globais e setoriais de desenvolvimento, no sentido de consolidar o modelo econômico definido nacionalmente.

No início do governo de João Goulart foi aprovada a Primeira Lei de Diretrizes e Bases da Educação (LDB), Lei n 4.024 de 20 de dezembro de 1961, que estava em tramitação no Congresso Nacional desde 1948. A LDB tinha como propósito nortear as estruturas de ensino no país, e subsidiar as políticas públicas educacionais nas três esferas de governo. Com o golpe civil-militar de 1964, novas diretrizes para a educação foram introduzidas através das reformas conservadoras das leis $\mathrm{n}^{\circ}$ 5.540/1968 (Reforma Universitária) e 5.692/1971 (Reforma do $1^{\circ}$ e $2^{\circ}$ graus). Assim, os dispositivos da LDB de 1961 que se referiam ao ensino primário, médio e superior foram revogados e substituídos pelo disposto nas duas leis (SAVIANI, 1999).

Em Santa Catarina, foi a partir da década de 1960, com a ascensão do desenvolvimentismo e do planejamento econômico, que a educação escolar passou a ser considerada, de maneira mais incisiva, como um fator imprescindível ao projeto de modernizar o Estado. Foi com o pretexto de modernizar a educação, para que esta pudesse responder às necessidades do modelo de desenvolvimento, que o sistema educacional foi reformulado. O tratamento dado à educação no primeiro Plano Estadual de Educação, elaborado no auge da ditadura por uma comissão composta por intelectuais ligados ao Estado e assessorados por organismos internacionais, foi marcado pela necessidade de atrelar a educação ao desenvolvimento econômico. A partir de então, o Estado passa a atribuir à educação papel fundamental no preparo do homem como força produtiva. O Documento Básico do Seminário Sócio-Econômico, realizado pela Federação das Indústrias de Santa Catarina - FIESC, entre 1959 e 1960, considerava a educação como área prioritária para o programa desenvolvimentista estadual - cujo carro chefe era a industrialização - e estabeleceu vinte metas educacionais a serem alcançadas pelo governo que iniciaria em 1961 (AURAS, 1998).

Tanto em nível nacional como estadual, ao longo dos anos de 1960 e 1970 houve a combinação de planos globais e setoriais. Após um período de recuo, orientado pelas 
políticas neoliberais dos anos de 1990, o planejamento voltou à tona no Brasil, tanto em nível nacional quanto estadual, combinando diversas políticas públicas em estratégias globais e setoriais. Neste sentido, esta pesquisa se justifica pela relevância do tema na história das políticas educacionais no Brasil e em Santa Catarina, e pela lacuna que há nos estudos em Santa Catarina que abordem a relação entre Economia e Educação, numa perspectiva histórica, social e política.

Entendemos que as leis, diretrizes e planos educacionais, assim como os planos de governo catarinenses, foram elaborados dentro de um contexto maior, orientado pelo modelo de desenvolvimento incorporado pelo Brasil e pela concepção política dominante em cada época, ao mesmo tempo em que seus conteúdos também influenciaram a criação de novas concepções sócio-educacionais. Buscaremos compreender as tensões e permanências em torno dessas concepções.

Tomamos como concepção de desenvolvimento a de Furtado (2004), na qual ele diferencia crescimento econômico de desenvolvimento. Para o autor, o crescimento econômico não leva necessariamente à eliminação das desigualdades sociais, pelo contrário, pode ocorrer, como tem ocorrido no Brasil, fundando-se na preservação dos privilégios das elites, que satisfazem seu afã de modernização. Já o desenvolvimento diferencia-se, para o autor, pelo seu projeto social subjacente, ou seja, dispor de recursos para investir não é condição suficiente para preparar um melhor futuro para a massa da população (FURTADO, 2004). O crescimento só se metamorfoseia em desenvolvimento quando há um projeto social subjacente, que prioriza a efetiva melhoria das condições de vida da população. E essa metamorfose, segundo o autor, não se dá espontaneamente, ela deve ser fruto da realização de um projeto, que ocorre como expressão de uma vontade política. Para Furtado (2004), o desenvolvimento econômico e social não resulta, portanto, de uma evolução automática, inercial, mas de opções políticas orientadas para a formação de uma sociedade apta a assumir um papel dinâmico nesse processo.

\section{Trajetória de gastos por funções e subfunções}

A trajetória da despesa realizada pelo estado de Santa Catarina com a função educação desde 1944 até 2010, apresentada no Gráfico 1, mostra um movimento de permanência do elevado gasto do Estado com educação, apesar das oscilações no 
percentual empregado em alguns períodos. Historicamente, os governos catarinenses vêm destinando expressivos montantes para a função Educação, que representam parte significativa do total de suas despesas. A média geral de gastos, em todo o período apresentado no Gráfico 1, foi de 18,53\% da despesa total realizada do Estado.

Houve períodos em que se gastou mais de um quarto da despesa total com a função. Os períodos em que houve maior volume despendido foram os anos 1949 e 1950, durante o governo de Aderbal Ramos da Silva (PSD-PTB), atingindo 25,32\% e 26,01\%, respectivamente; e, nos anos de 1966 e 1967, com 24,62\% e 26,04\%, no governo de Ivo Silveira (PSD-PTB), durante a execução do PLAMEG II. Durante todo o período, o menor percentual empregado foi $12,77 \%$ no ano de 1997 , durante o governo de Paulo Afonso Vieira, do PMDB. A década de 1990 foi marcada pela ascensão de políticas neoliberais, e um encolhimento do Estado. Com esse movimento houve um recuo de gastos com educação. No início dos anos 2000 ocorreu breve retomada do crescimento do gasto educacional.

Se observarmos a média de gastos por décadas, a década de 1940 (1944-1950) tem a maior média, 20,92\%; seguida pela década de 1960, com 20,41\%; e, a década de 1980, com 19,67\%. A menor média de gastos se deu na década de 1990, com 14,98\% da despesa realizada total. Desde a década de 1930 até meados da década de 1970, o Brasil vivia um ciclo de crescimento econômico, e Santa Catarina, seguindo o movimento geral da economia brasileira, a partir de meados da década de 1940, passa pelo processo de diversificação e ampliação da sua base produtiva, alcançando altos índices de crescimento até a década de 1970. Na década de 1980, quando o país já sentia mais fortemente os efeitos do endividamento e da crise fiscal do Estado, a média de crescimento do PIB catarinense já havia caído pela metade em relação a década anterior, mas se mantinha em níveis mais altos do que a média nacional. 
Gráfico 1 - Participação da despesa realizada com a função educação nos gastos totais do Estado (1944-2010) (em \%)

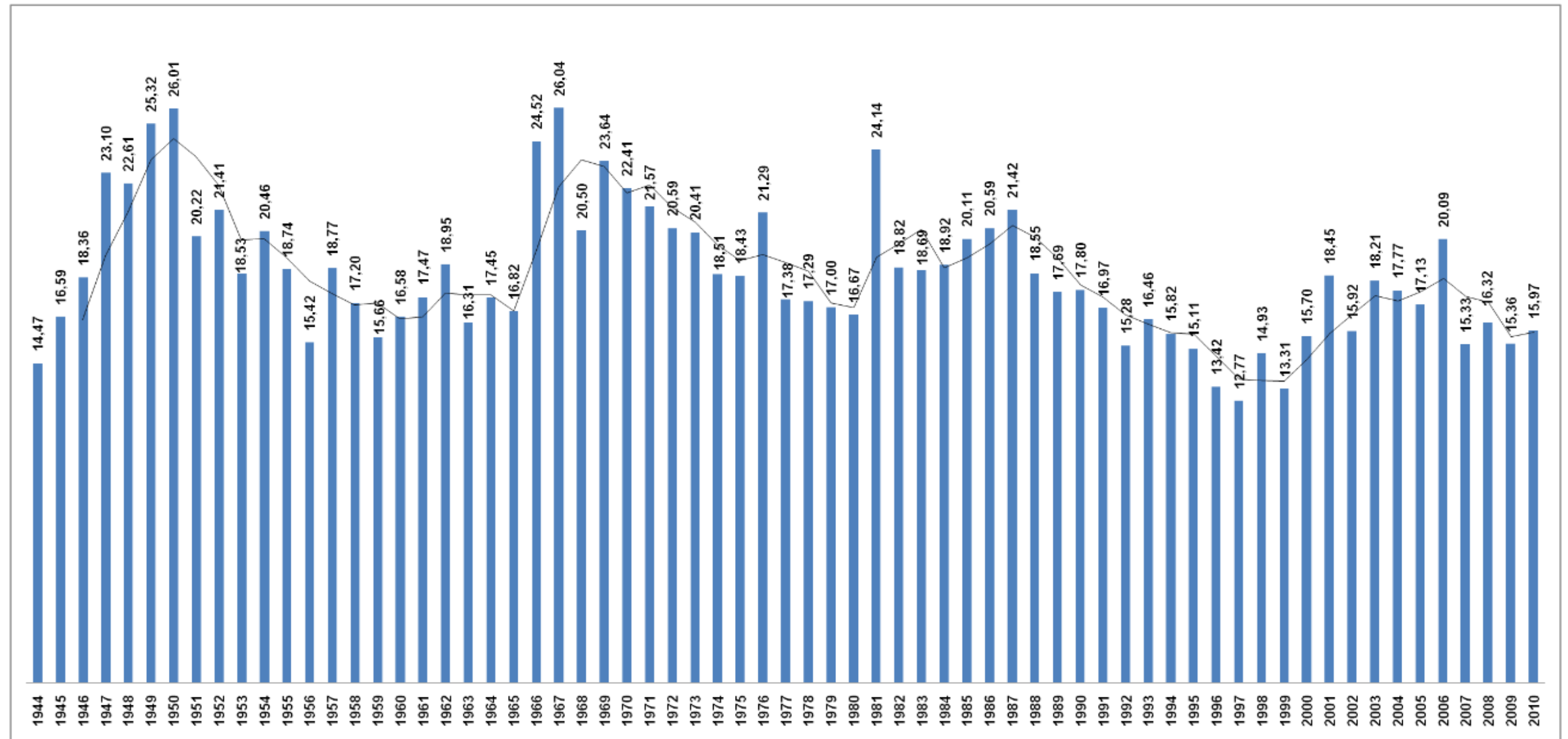

Fonte: IBGE, 1946-1952, 1953a, 1953b, 1954-1959, 1961-1963, 1966, 1968-1984; SANTA CATARINA, 1957-1960, 1962, 1964-1971, 1974-1976, 1978, 1980-1981, 19841995, 1996a, 1997-1999, 2000a, 2001-2011. (Elaborado pela autora) 
Revista Catarinense de Economia - RCE

APEC - Associação dos Pesquisadores em Economia Catarinense

10 Semestre de 2018 - www.apec.pro.br/rce

Entre a década de 1950 e o final da década de 1970 em Santa Catarina, surge e se fortalece o planejamento econômico em busca do desenvolvimento, tendo como um dos pilares do desenvolvimento a melhoria da educação no Estado, seja ela direcionada para melhorar os índices de desenvolvimento humano, ou para atender as demandas do mercado de trabalho e os interesses da classe empresarial. No final da década de 1980 e principalmente durante a década de 1990, com a ascensão neoliberal, verificou-se um encolhimento da participação do Estado na economia e os planos de governos se orientam também nesse sentido, havendo um encolhimento nos gastos com educação. Analisando o movimento geral em todo o período, constata-se que houve uma redução da participação da despesa realizada com educação nos gastos totais do Estado, o que decorre do aumento da complexidade da sociedade e do estado, que levou ao aumento de funções e serviços para os quais os recursos do orçamento estadual são destinados.

Ao compararmos a despesa realizada com a função educação às despesas com as demais funções, observa-se que esta função foi uma das que mais receberam recursos do Estado. Durante o período analisado, houve mudanças na legislação que normatiza a forma de apresentação dos gastos governamentais nas prestações de contas dos governos estaduais. No período que antecede 1964, a classificação era feita por serviços e subserviços, de acordo com o Decreto-lei no 2.416/40. Após 1964, a classificação das despesas se dá em funções e subfunções, sendo normatizada pela Lei $\mathrm{n}^{\circ} 4.320 / 64$, que permanece vigente até o final do período analisado. Em função dessa mudança, a apresentação dos gastos foi dividida em duas partes, conforme apresentado nas Tabelas 1 e 2 .

Observa-se nos relatórios de prestações de contas do governo que mesmo após 1964 ocorram algumas mudanças na forma como os dados são apresentados, incluindo umas funções e excluindo outras, juntando umas e separando outras. A maioria destas contabilizamos no agregado Outras Funções, da Tabela 3. Analisando-se a distribuição dos gastos por serviços no período de 1956 a 1963, constata-se que o maior percentual de gastos estava concentrado em Encargos Diversos, com média de 33,85\% dos gastos totais; seguido de Educação (16,80\%); Serviços de Utilidade Pública (16,34\%); Administração Geral (7,70\%); Segurança Pública e Assistência Social (6,98\%); Saúde Pública (4,93\%); Exação e Fiscalização Financeira (4,57\%); Fomento (4,09\%); Serviços Industriais (2,53\%); e, Dívida Pública $(2,20 \%)$.

No período de 1964 a 2010, ao observarmos as funções que tiveram maiores montantes de gastos, é possível perceber que na maioria dos anos, a função Educação só recebeu menos 
recursos do que a função Administração, cuja média no período atingiu 27,16\%. Cabe lembrar que até o ano de 1999, estavam contabilizados dentro desta função os valores de arrecadação de impostos que seriam transferidos aos municípios. A partir de 1999, essa cifra passou a ser computada dentro da função Encargos Especiais (contabilizado na Tabela 2 dentro do agregado Outras Funções), em decorrência das alterações promovidas pela Portaria $n^{\circ} 42$, de 14 de abril de 1999, do Ministério de Estado do Orçamento e Gestão. De 1964 a 2010, a média de gastos com Educação foi a segunda maior, representando 18,28\% do total das despesas realizadas; seguido pela função Assistência e Previdência com 10,17\%; Transportes e Obras (9,46\%); Segurança Pública $(7,06 \%)$, uma série crescente ao longo do período; Saúde, com 6,81\%; Judiciária (5,21\%), com expressivo aumento nas últimas décadas; e, Agricultura (3,59\%). Tiveram menor participação as funções Legislativa (2,24\%), Indústria, Comércio e Serviços (1,66\%) e Habitação e Urbanismo (1,37\%). 
Revista Catarinense de Economia - RCE

APEC - Associação dos Pesquisadores em Economia Catarinense

10 Semestre de 2018 - www.apec.pro.br/rce

Tabela 1 - Participação (em \%) da despesa realizada por funções em relação aos gastos totais do Estado de Santa Catarina (1955-1963)

\begin{tabular}{|c|c|c|c|c|c|c|c|c|c|c|c|}
\hline Ano & $\begin{array}{c}\text { Administração } \\
\text { geral }\end{array}$ & $\begin{array}{c}\text { Exação e } \\
\text { fiscalização } \\
\text { financeira }\end{array}$ & $\begin{array}{l}\text { Segurança pública } \\
\text { e assistência social }\end{array}$ & $\begin{array}{l}\text { Educação } \\
\text { pública }\end{array}$ & $\begin{array}{l}\text { Saúde } \\
\text { pública }\end{array}$ & Fomento & $\begin{array}{l}\text { Serviços } \\
\text { industriais }\end{array}$ & $\begin{array}{l}\text { Dívida } \\
\text { pública }\end{array}$ & $\begin{array}{c}\text { Serviços de } \\
\text { utilidade pública }\end{array}$ & $\begin{array}{c}\text { Encargos } \\
\text { diversos }\end{array}$ & Total \\
\hline 1956 & 8,41 & 4,51 & 7,42 & 15,42 & 5,39 & 5,03 & 4,36 & 2,51 & 16,86 & 30,09 & 100,00 \\
\hline 1957 & 9,99 & 5,63 & 7,63 & 18,77 & 5,29 & 5,08 & 1,82 & 1,67 & 13,51 & 30,62 & 100,00 \\
\hline 1958 & 7,70 & 4,89 & 6,88 & 17,20 & 4,91 & 4,22 & 1,82 & 2,03 & 11,77 & 38,58 & 100,00 \\
\hline 1959 & 7,09 & 4,39 & 6,84 & 15,66 & 5,12 & 3,50 & 2,50 & 1,87 & 4,33 & 48,70 & 100,00 \\
\hline 1961 & 7,11 & 3,96 & 7,01 & 17,47 & 4,65 & 2,80 & 2,03 & 1,05 & 13,88 & 40,03 & 100,00 \\
\hline 1963 & 5,89 & 4,04 & 6,10 & 16,31 & 4,25 & 3,92 & 2,67 & 4,08 & 37,67 & 15,07 & 100,00 \\
\hline
\end{tabular}

Fonte: SANTA CATARINA, 1957-1960, 1962, 1964. (Elaborado pela autora)

Tabela 2 - Participação (em \%) da despesa realizada por funções em relação aos gastos totais do Estado de Santa Catarina (1964-2010)

\begin{tabular}{|c|c|c|c|c|c|c|c|c|c|c|c|c|c|}
\hline Ano & Legislativa & Judiciária & Administração & $\begin{array}{c}\text { Segurança } \\
\text { Pública }\end{array}$ & $\begin{array}{c}\text { Assistência } \\
\text { e } \\
\text { Previdência }\end{array}$ & Saúde & Educação & $\begin{array}{c}\text { Habitação e } \\
\text { Urbanismo }\end{array}$ & Agricultura & $\begin{array}{l}\text { Indústria, } \\
\text { Comércio e } \\
\text { Serviços }\end{array}$ & $\begin{array}{c}\text { Transporte } \\
\text { e Obras }\end{array}$ & $\begin{array}{c}\text { Outras } \\
\text { Funções }\end{array}$ & Total \\
\hline 1964 & - & - & 51,31 & - & - & 4,43 & 17,45 & 13,01 & 2,68 & - & - & 11,12 & 100,00 \\
\hline 1965 & - & - & 49,35 & - & - & 4,31 & 16,82 & 12,59 & 2,37 & - & - & 14,56 & 100,00 \\
\hline 1966 & - & - & 37,83 & - & - & 4,70 & 24,52 & 12,86 & 2,10 & - & 0,04 & 17,96 & 100,00 \\
\hline 1967 & - & - & 43,14 & - & - & 4,77 & 26,04 & 8,59 & 2,42 & - & 0,03 & 15,00 & 100,00 \\
\hline 1968 & - & - & 51,48 & 4,90 & 7,87 & 4,11 & 20,50 & 0,05 & 2,01 & - & 8,21 & 0,87 & 100,00 \\
\hline 1969 & - & - & 37,62 & 5,70 & 8,84 & 4,46 & 23,64 & 0,13 & 2,50 & 2,91 & 8,87 & 5,32 & 100,00 \\
\hline 1970 & - & - & 33,25 & 5,91 & 8,71 & 3,83 & 22,41 & 1,04 & 2,12 & 0,55 & 5,54 & 16,64 & 100,00 \\
\hline 1971 & - & - & 16,28 & 5,08 & 9,93 & 4,45 & 21,57 & 0,21 & 3,10 & 0,32 & 16,16 & 22,90 & 100,00 \\
\hline 1972 & - & - & 17,84 & 5,21 & 9,33 & 4,25 & 20,59 & 0,20 & 2,56 & 0,28 & 15,90 & 23,83 & 100,00 \\
\hline 1973 & - & - & 16,61 & 5,30 & 8,80 & 6,25 & 20,41 & 0,18 & 2,55 & 0,31 & 14,18 & 25,40 & 100,00 \\
\hline 1974 & - & - & 15,67 & 5,31 & 7,87 & 5,75 & 18,51 & 0,12 & 2,29 & 1,19 & 22,63 & 20,64 & 100,00 \\
\hline 1975 & 1,66 & 3,44 & 36,93 & 4,93 & - & 4,51 & 18,43 & - & 1,82 & 0,20 & 25,23 & 2,85 & 100,00 \\
\hline 1977 & 1,55 & 2,73 & 14,68 & 5,14 & 7,15 & 5,50 & 17,38 & 0,09 & 1,93 & 4,43 & 24,57 & 14,85 & 100,00 \\
\hline 1979 & 1,59 & 2,51 & 31,13 & 4,71 & 6,55 & 5,57 & 17,00 & 0,17 & 1,87 & 3,32 & 22,96 & 2,63 & 100,00 \\
\hline 1980 & 1,63 & 2,39 & 30,11 & 4,81 & 6,37 & 7,96 & 16,67 & 0,07 & 2,19 & 2,72 & 20,77 & 4,31 & 100,00 \\
\hline 1981 & 1,61 & 3,05 & 8,90 & 5,49 & 7,94 & 8,41 & 24,14 & - & 3,23 & 8,21 & 24,32 & 4,55 & 100,00 \\
\hline 1982 & 1,53 & 2,48 & 22,19 & 4,57 & 7,47 & 6,74 & 18,82 & - & 3,85 & 6,27 & 18,71 & 7,31 & 100,00 \\
\hline 1983 & 2,10 & 3,55 & 23,47 & 5,61 & 10,87 & 6,34 & 18,69 & 0,06 & 4,56 & 2,97 & 16,98 & 4,81 & 100,00 \\
\hline 1984 & 1,95 & 3,11 & 26,37 & 5,56 & 10,28 & 5,44 & 18,92 & 0,33 & 6,86 & 3,94 & 12,74 & 4,50 & 100,00 \\
\hline 1985 & 2,09 & 3,51 & 25,70 & 5,79 & 11,01 & 6,84 & 20,11 & 0,36 & 5,36 & 4,09 & 12,86 & 2,28 & 100,00 \\
\hline Artigo & & Revista Ca & arinense de Econo & mia, v. 2, n. 1 & 1 (2018), Florian & ópolis/SC & & & 57 & & & & \\
\hline
\end{tabular}


Revista Catarinense de Economia - RCE

APEC - Associação dos Pesquisadores em Economia Catarinense 10 Semestre de 2018 - www.apec.pro.br/rce

\begin{tabular}{|c|c|c|c|c|c|c|c|c|c|c|c|c|c|}
\hline 1986 & 2,10 & 3,51 & 25,59 & 5,70 & 10,32 & 6,89 & 20,59 & 0,45 & 4,67 & 3,86 & 13,20 & 3,12 & 100,00 \\
\hline 1987 & 2,01 & 3,90 & 25,59 & 5,95 & 12,07 & 7,26 & 21,42 & 0,25 & 4,88 & 3,11 & 9,98 & 3,58 & 100,00 \\
\hline 1988 & 2,03 & 3,20 & 18,21 & 6,74 & 12,43 & 12,69 & 18,55 & 0,72 & 6,20 & 2,92 & 11,92 & 4,40 & 100,00 \\
\hline 1989 & 2,02 & 3,57 & 38,76 & 7,67 & 13,76 & 5,48 & 17,69 & 0,22 & 3,42 & 1,22 & 4,78 & 1,42 & 100,00 \\
\hline 1990 & 1,88 & 4,09 & 38,70 & 8,69 & 13,76 & 5,27 & 17,80 & 0,16 & 3,02 & 0,63 & 5,06 & 0,94 & 100,00 \\
\hline 1991 & 1,87 & 4,37 & 39,64 & 7,62 & 11,42 & 5,06 & 16,97 & 0,35 & 4,82 & 1,67 & 5,82 & 0,40 & 100,00 \\
\hline 1992 & 1,72 & 4,53 & 39,78 & 6,48 & 11,87 & 4,16 & 15,28 & 0,98 & 5,09 & 1,69 & 8,08 & 0,36 & 100,00 \\
\hline 1993 & 1,85 & 6,06 & 30,76 & 7,51 & 12,39 & 4,79 & 16,46 & 0,60 & 6,78 & 2,11 & 10,58 & 0,10 & 100,00 \\
\hline 1994 & 1,65 & 4,01 & 40,43 & 5,53 & 10,21 & 5,30 & 15,82 & 0,59 & 4,57 & 1,41 & 10,40 & 0,07 & 100,00 \\
\hline 1995 & 2,04 & 5,49 & 37,89 & 6,96 & 13,32 & 5,56 & 15,11 & 0,62 & 5,36 & 1,79 & 4,83 & 1,02 & 100,00 \\
\hline 1996 & 1,91 & 4,96 & 43,87 & 5,54 & 13,39 & 4,24 & 13,42 & 0,34 & 4,17 & 0,98 & 6,14 & 1,04 & 100,00 \\
\hline 1997 & 2,09 & 4,78 & 45,76 & 5,29 & 14,95 & 3,76 & 12,77 & 0,39 & 4,18 & 0,71 & 4,30 & 1,03 & 100,00 \\
\hline 1998 & 2,52 & 6,71 & 36,35 & 9,14 & 19,23 & 4,32 & 14,93 & 0,52 & 4,52 & 0,14 & 0,35 & 1,27 & 100,00 \\
\hline 1999 & 2,56 & 5,88 & 44,78 & 8,34 & 15,22 & 4,00 & 13,31 & - & 4,60 & 0,18 & 0,15 & 0,97 & 100,00 \\
\hline 2000 & 2,30 & 4,85 & 23,02 & 8,07 & 0,25 & 3,56 & 15,70 & 0,11 & 3,31 & 0,19 & 0,07 & 38,58 & 100,00 \\
\hline 2001 & 2,73 & 6,14 & 6,63 & 10,04 & 5,77 & 8,59 & 18,63 & 0,26 & 3,47 & 0,55 & 4,70 & 32,50 & 100,00 \\
\hline 2002 & 2,37 & 5,29 & 19,34 & 8,83 & 4,09 & 8,07 & 16,07 & 0,18 & 3,68 & 0,41 & 4,22 & 27,46 & 100,00 \\
\hline 2003 & 2,61 & 7,00 & 6,47 & 10,27 & 4,78 & 10,45 & 18,38 & 0,09 & 3,83 & 0,46 & 5,43 & 30,24 & 100,00 \\
\hline 2004 & 2,78 & 7,47 & 7,43 & 11,17 & 4,47 & 10,83 & 17,93 & 0,19 & 3,51 & 0,17 & 4,05 & 30,01 & 100,00 \\
\hline 2005 & 2,65 & 7,86 & 8,92 & 11,78 & 4,30 & 10,21 & 17,29 & 0,17 & 3,72 & 0,17 & 4,11 & 28,81 & 100,00 \\
\hline 2006 & 3,41 & 9,44 & 7,72 & 11,52 & 11,22 & 14,46 & 20,80 & 0,23 & 4,29 & 0,49 & 4,08 & 12,35 & 100,00 \\
\hline 2007 & 3,44 & 10,19 & 7,29 & 11,55 & 17,08 & 13,78 & 16,09 & 0,26 & 3,69 & 0,63 & 3,96 & 12,03 & 100,00 \\
\hline 2008 & 3,48 & 9,62 & 26,71 & 1,61 & 15,18 & 9,64 & 16,69 & 1,32 & 0,80 & 0,02 & 2,01 & 12,93 & 100,00 \\
\hline 2009 & 3,11 & 8,44 & 5,72 & 11,66 & 17,94 & 14,86 & 15,79 & 0,96 & 3,27 & 0,55 & 4,97 & 12,73 & 100,00 \\
\hline 2010 & 3,17 & 8,92 & 6,86 & 11,65 & 18,38 & 14,70 & 16,45 & 1,53 & 3,18 & 0,43 & 2,91 & 11,81 & 100,00 \\
\hline
\end{tabular}

Fonte: IBGE, 1971, 1972, 1980, 1981, 1982; SANTA CATARINA, 1965-1971, 1974-1976, 1978, 1980, 1981, 1984-1995, 1996a, 1996b, 1997-1999, 2000a, 2000b, 20012011. (Elaborado pela autora) 
Revista Catarinense de Economia - RCE

APEC - Associação dos Pesquisadores em Economia Catarinense

1은 Semestre de 2018 - www.apec.pro.br/rce

No final da década de 1990, observou-se uma ascensão dos gastos com Assistência e Previdência Social, que nos anos de 1997 a 1999, ultrapassam em termos relativos, os gastos com Educação. O mesmo voltou a acontecer no final da década de 2000, a partir de 2007. Em meados da década de 1970 e início dos 1980, foi a função Transportes e Obras, que acendeu a uma participação relativa maior do que a Educação, passando esta última a ser a terceira maior. A soma Outras Funções, com média de 10,92\%, embora não muito expressiva durante alguns anos, apresentou muitas oscilações, por ser a soma de várias funções que apareceram e desapareceram ao longo do período.

Dentro desta soma, as funções com maior participação foram Encargos Gerais/Especiais e as Transferências aos Municípios, que aparecem como funções nos relatórios apenas durante os anos 1970-1974 e 1977. Exatamente durante estes anos, houve uma diminuição da participação da função Administração nos gastos totais. No período seguinte, as transferências aos municípios voltaram a ser computadas como subfunção dentro da função administração, aumentando significativamente sua participação no orçamento. A partir de 2000, essas transferências passaram a ser computadas como subfunções da função Encargos Especiais, quando reduzui novamente a participação da função Administração no gasto total.

Com relação a distribuição dos gastos realizados com a função educação por subfunções (Gráfico 2), o Ensino Primário/Fundamental representou, durante a maior parte do período analisado, em média, 50,39\% dos gastos totais realizados, seguido pelo gasto com Administração (12,69\%), e com o Ensino Secundário/Médio (10,44\%), como pode ser observado no Gráfico 2. O Ensino Superior recebeu em média 5,75\% dos recursos, havendo chegado a receber em alguns períodos mais de $10 \%$ dos recursos, como no início da década de 1990, e no final dos anos 2000. A subfunção, Assistência a Educandos, recebeu em torno de $2,48 \%$ dos recursos, deixando de ser contabilizada como subfunção a partir de 1999. O mesmo aconteceu com Difusão Cultural e Educação Física e Desportos, que deixaram de ser contabilizadas como subfunções. Estas receberam durante o período 1,09\% e 1,39\%, respectivamente, do total das despesas com a função Educação. Educação Especial e Ensino Supletivo receberam em média $1,52 \%$ e $0,87 \%$ dos recursos. A Educação Pré-Escolar, que passa a aparecer nos relatórios somente a partir do ano de 1990, recebeu em torno de 1,16\% dos recursos.

Quanto aos gastos com Ensino Técnico e Profissional, embora nos planos de governo se dê bastante ênfase para esta área, deparou-se nos relatórios de prestação de contas com poucas informações disponíveis para mensurar os gastos efetivos com ensino profissionalizante. $\mathrm{O}$ 
Ensino Técnico e Profissional apareceu como subfunção nos relatórios durante poucos anos da década de 1970 e em 1969, e voltou a aparecer novamente somente a partir de 1999, sob a nomenclatura Ensino Profissional, em função das mudanças na classificação de subfunções promovidas pela Portaria $\mathrm{n}^{\circ}$ 42, de 14 de abril de 1999, do Ministério de Estado do Orçamento e Gestão. Durante o curto período em que apareceram nos relatórios, os gastos destinados a esta subfunção foram pouco expressivos, $0,24 \%$ do total da função educação em 1969, e 0,94\% em 1970. Na década de 2000, a média de gastos da subfunção foi de 0,38\%. É possível que os recursos destinados para o ensino profissionalizante tenham sido contabilizados junto com a subfunção Ensino Secundário/Médio. Não foram encontrados dados por subfunções para o período anterior a 1964.

Gráfico 2 - Participação das subfunções no total da despesa realizada com a função educação $(\mathrm{em} \%)$

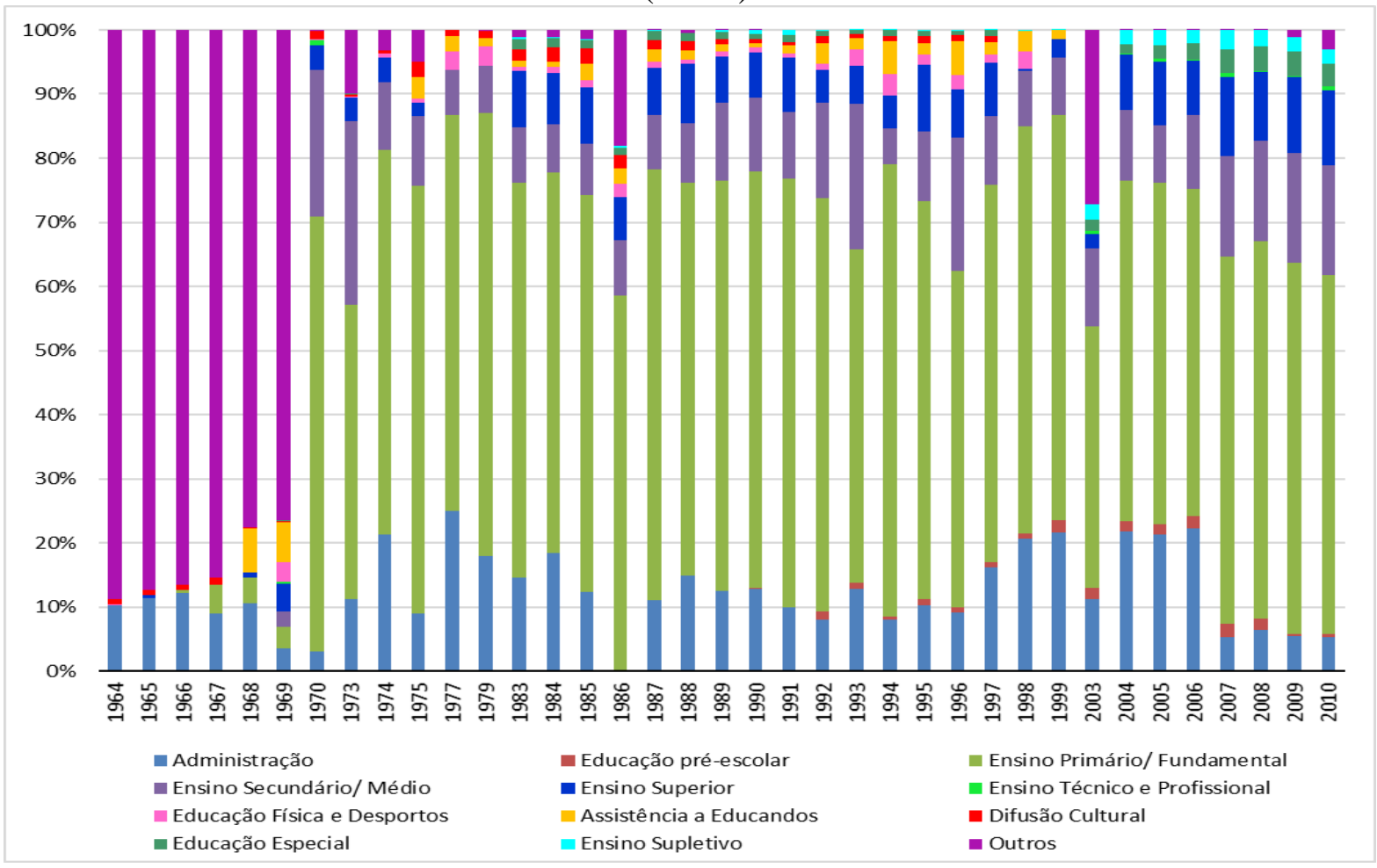

Fonte: SANTA CATARINA, 1965-1971, 1974-1976, 1978, 1980, 1984-1995, 1996a, 1997-1999, 2000a, 20042011. (Elaborado pela autora)

Analisando-se a participação da despesa realizada com a função educação em relação ao PIB de Santa Catarina, no período de 1961 a 2010, constata-se, conforme o Gráfico 3, que os períodos com maior gasto relativo foram durante a década de 1960, na segunda metade da década de 1980 e no início dos anos 2000. Os níveis mais baixos do gasto em relação ao PIB estadual foram em 1983 (1,27\%), 1984 (1,24), 1998 (1,33\%) e 1999 (1,16\%). Se observarmos 
a média da participação por décadas, a década de 1960 obteve a maior média, 1,93\%, seguida da década de 1980,1,78\%, e da década de 2000, com 1,72\%. As décadas de 1970 e 1990 obtiveram as menores médias de participação em relação ao PIB, com 1,52\% e 1,55\%, respectivamente.

Gráfico 3 - Participação da despesa realizada com a função educação sobre o PIB de Santa Catarina (1961-2010)

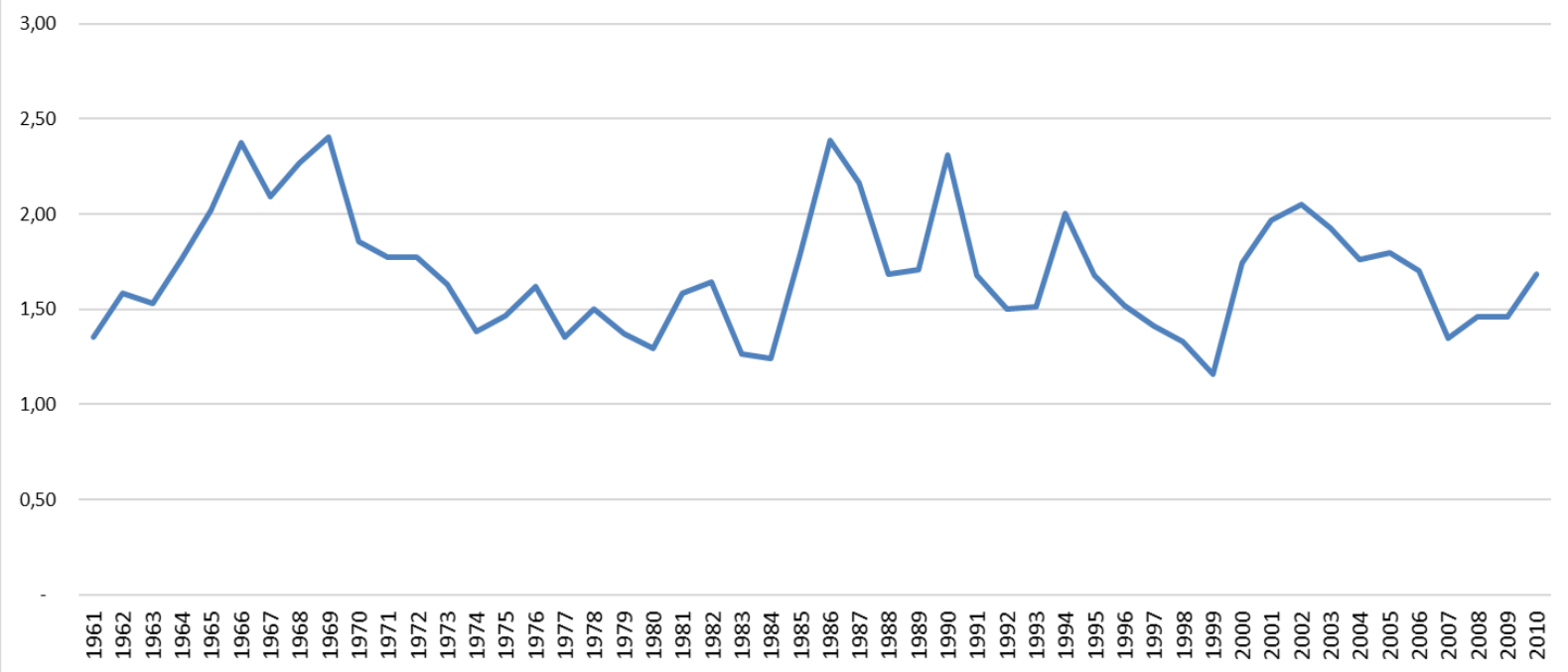

Fonte: IBGE, 1962-1963, 1966, 1968-2010; SANTA CATARINA, 1962, 1964-1971, 1974-1976, 1978, 19801981, 1984-1995, 1996a, 1997-1999, 2000a, 2001-2011. (Elaborado pela autora)

Portanto, em relação aos gastos do governo estadual com a função Educação, é possível afirmar que historicamente corresponderam a parte significativa dos gastos totais do Estado catarinense. Em relação a despesa realizada com as demais funções, a função educação, na maior parte do período analisado, recebeu recursos em montante menor do que os da função Administração, esta que engloba os valores a serem transferidos para os municípios, inflando os dados apresentados. Ao excluir-se o valor destinado aos municípios, nenhuma outra função manteve durante todo o período, percentual tão elevado quanto a educação em relação às despesas totais do Estado. No que se refere ao gasto por subfunções, o Ensino Primário/Fundamental teve a maior participação, representando em torno de $50 \%$ do total de gastos com educação. E em relação ao PIB, a participação dos gastos com a função oscilou entre 2,41\% no final da década de 1960 até 1,16\% na década de 1990, mantendo um movimento com poucas oscilações.

\section{Despesa realizada com educação por períodos e planos de governo}


Revista Catarinense de Economia - RCE

APEC - Associação dos Pesquisadores em Economia Catarinense

10 Semestre de 2018 - www.apec.pro.br/rce

Analisando-se a trajetória do planejamento estadual em Santa Catarina, especificamente no que tange as diretrizes e metas para a educação apresentadas nos planos de governo, é possível perceber intenções e movimentos associados a elaboração e execução de cada plano no decorrer do período estudado. Nesta seção, compara-se a previsão de gastos para a educação em cada plano de governo com a média da despesa realizada com a função, por período de governo e de execução de cada plano.

O Plano de Obras e Equipamentos (POE), primeiro plano de governo elaborado para o Estado de Santa Catarina, foi enviado à Assembleia Legislativa em março de 1955, pelo governador Irineu Bornhausen (1951-1955/UDN) em seu último ano de mandato. O plano era previsto para um período de execução de dez anos e a previsão de gastos por setores estava assim dividida: $45 \%$ para estradas de rodagem; $35 \%$ para energia elétrica; $10 \%$ para a agricultura; e, os 10\% restantes deveriam ser divididos entre saúde e educação (BORNHAUSEN, 1955). Pouco se menciona sobre metas para a educação neste plano, no entanto, percebe-se que o foco era a construção e aparelhamento de jardins de infância. A média da despesa realizada com educação no governo de Irineu Bornhausen foi de 19,87\%. Em 1955, primeiro ano de execução do POE foi de 18,74\%. Com o apoio de Bornhausen, em 1956, foi eleito Jorge Lacerda para governador do Estado entre 1956 e 1960, assumindo o compromisso de dar continuidade a execução do POE. Durante seu período de governo, a média de gastos com a função educação foi de 16,76\%. Entre 1955 e 1961, período de execução independente do POE (após 1961, passou a ser incorporado pelo PLAMEG), a média de gastos foi de $17,21 \%$.

Em 1961 assume o governo do Estado, Celso Ramos (PSD-PTB), lançando o Plano de Metas do Governo (PLAMEG), previsto para ser executado até o final de seu mandato, em 1965. Este plano estava orçado em 17,5 bilhões de cruzeiros, que seriam distribuídos em três grandes áreas, O Homem, com 26,7\% dos recursos, o Meio com 58,3\%, e Expansão Econômica com 15\%. Dentro da área O Homem, estavam previstos 11,6\% dos recursos totais do plano para educação e cultura, que deveriam ser utilizados na ampliação da estrutura física, construção de novas escolas e concessão de bolsas de estudo. $\mathrm{O}$ foco era a ampliação de vagas (SANTA CATARINA, 1961). Durante a execução deste plano, a média de gastos com a função educação foi de $17,40 \%$.

Com a eleição de Ivo Silveira também pelo PSD-PTB, em 1966, lançou-se o Plano de Metas do Governo II (PLAMEG II) - 1966-1970, dando continuidade ao plano do governo anterior. O PLAMEG II estava orçado em 216 milhões de cruzeiros novos, que deveriam ser 
Revista Catarinense de Economia - RCE

APEC - Associação dos Pesquisadores em Economia Catarinense

1 은 Semestre de 2018 - www.apec.pro.br/rce

assim distribuídos: $62 \%$ para expansão econômica; $17 \%$ para melhoria das condições sociais; $15 \%$ para valorização dos recursos humanos; e $6 \%$ para a melhoria dos meios administrativos (SILVEIRA, 1966). O foco para a educação continuava sendo a ampliação da oferta de vagas. Nesse período, o gasto com a função educação atingiu a maior média de toda a trajetória estudada, alcançando $23,42 \%$ do total da despesa realizada.

O Projeto Catarinense de Desenvolvimento (PCD), lançado no governo de Colombo Machado Salles, da Arena, para o período de 1971 a 1974, estava orçado em 5,6 bilhões de cruzeiros, distribuídos entre os seguintes setores: Agricultura (22,7\%); Indústria (21,8\%); Transporte (20,9\%); Saneamento (14,9\%); Energia (5,6\%); Outras áreas (14,1\%) (SALLES, 1971). Neste plano não havia um percentual específico de gasto destinado para a educação, mas as principais metas para a educação estavam relacionadas ao investimento em tecnologia, atendimento das demandas do mercado de trabalho, modernização da indústria, etc., e colocavam a educação como um instrumento do progresso técnico. $\mathrm{O}$ foco passou a ser o ensino profissionalizante. Entre 1971 a 1974, a despesa realizada com a função educação ficou em torno de $20,27 \%$ dos gastos totais.

Em 1975, elegeu-se para o governo de Santa Catarina Antônio Carlos Konder Reis, da Arena, tendo como linha de orientação o Plano de Governo (PG) para ser executado entre 1975 e 1978. Este plano tinha uma previsão de gastos, mas foi lançado o orçamento plurianual com previsão de gastos de 12,1 bilhões de cruzeiros, sendo assim distribuídos: 24,7\% para Transporte; 17\% para Educação; 11,3\% para Administração e Planejamento; 3,8\% para Saúde; 2,0\% para a Indústria; e, 1,7\% para a Agricultura (KONDER REIS, 1975). As metas para a educação, neste período, estavam voltadas a ampliação ensino profissionalizante e para a incorporação dos avanços tecnológicos. Durante o período de governo de Antônio Carlos Konder Reis, a média de gastos com a função educação foi de $18,60 \%$ da despesa orçamentária total executada.

O Plano de Ação (PA), lançado em 1979, pelo governador Jorge Konder Bornhausen, da Arena, tinha previsão de execução até o final de seu mandato, em 1982. Estava dividido em três grandes programas, assim nomeados: Campo Psicossocial; Campo Econômico; Organização Administrativa e Planejamento (BORNHAUSEN, 1979). Este plano não estava vinculado a um orçamento com previsão de gastos, apenas apresentava as metas e intenções do governo. Para a educação, entre outras metas encontravam-se a integração entre comunidade e escola, ampliação da assistência escolar, valorização dos profissionais da 
Revista Catarinense de Economia - RCE

APEC - Associação dos Pesquisadores em Economia Catarinense

1은 Semestre de 2018 - www.apec.pro.br/rce

educação, a revisão dos currículos, melhoria da qualidade do ensino e a descentralização da administração. Entre 1979 e 1982, a média de gastos realizados com educação foi de 19,16\%.

A Carta dos Catarinenses, lançada pelo governador Esperidião Amin, do PDS, serviu de orientação ao governo durante o período de 1983-1986. Este plano também não apresentava um orçamento com previsão de gastos por áreas da economia e da sociedade. Apresentava apenas as intenções do governo. Estava dividido em três grandes setores: o Administrativo; o Social; e o Econômico e de Infraestrutura (HELOU FILHO, 1982). Para a educação suas metas estavam ligadas a descentralização da administração, ampliação do atendimento aos alunos carentes (atendimento assistencial e merenda escolar), e a valorização do magistério. Nesse período a média de gastos realizada com a função educação foi de 19,58\%.

O plano Rumo à Nova Sociedade Catarinense, do governador Pedro Ivo Campos, do PMDB, serviu de orientação ao governo no período entre 1987 e 1990. Da mesma forma como os planos anteriores, este plano apresentava apenas as intenções do governo, sem um planejamento de gastos vinculado ao orçamento. Estava dividido em quatro áreas: políticoinstitucional, social, econômica e de infraestrutura, e a ambiental (CAMPOS, 1987). Para a educação visava a melhoraria da qualidade do ensino, a valorização dos profissionais da educação e a integração da escola à realidade social, entre outras metas. Essas metas refletiram de alguma forma as pressões populares por uma escola mais democrática, em um momento em que o país estava saindo de um longo período ditatorial. Em termos de despesa realizada com educação, no governo de Pedro Ivo e Casildo Maldaner, a média com a função foi de $18,87 \%$ das despesas totais.

O Plano SIM, que orientou as ações do governo de Vilson Kleinübing (PFL) entre 1991-1994, estava dividido em cinco grandes áreas: metas fundamentais (saúde, instrução e moradia - com 45,6\% dos recursos); base (pleno emprego); dinamização sistema produtivo, com $31,7 \%$ dos recursos; infraestrutura, com $18 \%$, e sociedade de bem-estar, com 4,7\% (KLEINÜBING, 1990). Para a educação especificamente, deveriam ser destinados 13,75\% dos recursos, que seriam alocados em um Fundo para Modernização da Instrução. As metas estavam ligadas a modernização da educação e a utilização desta, como como instrumento para melhoria da renda e da produtividade. A média de gastos realizada com a função durante o período foi $16,13 \%$ em relação aos gastos totais do estado.

No governo neoliberal de Kleinübing foram promovidas profundas modificações na estrutura organizacional do Poder Executivo, que representaram um encolhimento do Estado. Com o Programa de Modernização do Governo - PMG aprovado pelas Leis nº 8.240 de 12 de 
abril de 1991 e $\mathrm{n}^{\mathrm{o}} 8.245$, de 18 de abril de 1991, somente neste primeiro ano de mandato, reduziu-se o número de Secretarias de Estado de 20 para 10; de Autarquias de 8 para 6; Fundações de 9 para 4; Empresas Públicas e Sociedades de Economia Mista de 22 para 21, com autorização legislativa para a transferência ao Município ou à iniciativa privada de 4 empresas; Sociedade Civil de 3 para 1; cargos em comissão de 3.431 para 672; e, funções gratificadas de 4203 para 2161 (SANTA CATARINA, 1991).

Tabela 3 - Planos de governo, previsão de gastos e percentual médio da despesa realizada com educação em relação aos gastos totais do Estado (1955-2010)

\begin{tabular}{|c|c|c|c|c|}
\hline Período & Governo & Plano de Governo & Previsão de gastos para educação por plano & $\begin{array}{l}\% \\
\text { média }\end{array}$ \\
\hline 1951-1955 & $\begin{array}{l}\text { Irineu Bornhausen } \\
\text { (UDN) }\end{array}$ & & & 19,87 \\
\hline $1956-1960$ & $\begin{array}{l}\text { Lacerda - Hülse } \\
\text { (PRP-UDN) }\end{array}$ & POE (1955-1965) & $10 \%$ para saúde e educação & 16,76 \\
\hline $1961-1965$ & $\begin{array}{l}\text { Celso Ramos } \\
\text { (PSD-PTB) }\end{array}$ & PLAMEG & $11,6 \%$ para educação e cultura & 17,40 \\
\hline 1966-1970 & $\begin{array}{l}\text { Ivo Silveira } \\
\text { (PSD-PTB) }\end{array}$ & PLAMEG II & $15 \%$ para valorização dos recursos humanos & 23,42 \\
\hline 1971-1974 & $\begin{array}{l}\text { Colombo M. Salles } \\
\text { (Arena) }\end{array}$ & PCD & educação não especificado & 20,27 \\
\hline $1975-1978$ & $\begin{array}{l}\text { Antonio C. Konder } \\
\text { Reis (Arena) }\end{array}$ & Plano de Governo & $17 \%$ para Educação & 18,60 \\
\hline 1979-1982 & $\begin{array}{l}\text { Jorge K. Bornhausen } \\
\text { (Arena) }\end{array}$ & Plano de Ação & sem previsão de gastos & 19,16 \\
\hline 1983-1986 & $\begin{array}{l}\text { Esperidião Amin } \\
\text { (PDS) }\end{array}$ & Carta dos Catarinense & sem previsão de gastos & 19,58 \\
\hline 1987-1990 & $\begin{array}{l}\text { Pedro Ivo - Casildo } \\
\text { Maldaner (PMDB) }\end{array}$ & $\begin{array}{l}\text { Ruma à Nova } \\
\text { Sociedade Catarinense }\end{array}$ & sem previsão de gastos & 18,87 \\
\hline 1991-1994 & $\begin{array}{l}\text { Vilson Kleinübing } \\
\text { (PFL) }\end{array}$ & Plano SIM & $\begin{array}{c}\text { 13,75\% para o Fundo para Modernização da } \\
\text { Instrução; }\end{array}$ & 16,13 \\
\hline 1995-1998 & $\begin{array}{l}\text { Paulo Afonso Vieira } \\
\text { (PMDB) }\end{array}$ & Viva Santa Catarina & sem previsão de gastos & 14,06 \\
\hline 1999-2002 & $\begin{array}{l}\text { Esperidião Amin } \\
\text { (PPB) }\end{array}$ & $\begin{array}{l}\text { Santa Catarina: Estado } \\
\text { Vencedor }\end{array}$ & sem previsão de gastos & 15,84 \\
\hline 2003-2006 & $\begin{array}{l}\text { Luiz Henrique da } \\
\text { Silveira (PMDB) }\end{array}$ & Plano 15 & sem previsão de gastos & 18,30 \\
\hline 2007-2010 & $\begin{array}{l}\text { Luiz Henrique da } \\
\text { Silveira (PMDB) }\end{array}$ & $\begin{array}{l}\text { Plano } 15 \text { II: a mudança } \\
\text { continua }\end{array}$ & sem previsão de gastos & 15,74 \\
\hline
\end{tabular}

Fonte: BORNHAUSEN, 1955; BORNHAUSEN, 1979; CAMPOS, 1986; HELOU FILHO, 1982, 1998; IBGE, 1946-1952, 1953a, 1953b, 1954-1959, 1961-1963, 1966, 1968-1984; KLEINÜBING, 1990; KONDER REIS, 1975; SALLES, 1971; SANTA CATARINA, 1957-1960, 1962, 1964-1971, 1974-1976, 1978, 1980-1981, 19841995, 1996a, 1997-1999, 2000a, 2001-2011; SILVEIRA, 1966; SILVEIRA, 2002, 2006; VIERA, 1994. (Elaborado pela autora)

O plano Viva Santa Catarina foi lançado em 1995, pelo governador Paulo Afonso Vieira, do PMDB, para orientar as ações de seu governo até 1998. O plano foi dividido em quatro áreas, assim denominadas: cidadania (geração de trabalho e renda); campo (valorização do homem e de seu trabalho); criança (construção do futuro); e modernização do Estado (VIEIRA, 1994). O ideário liberal ditou as metas para a educação: qualidade total, eficiência e eficácia e excelência na educação. O governo de Paulo Afonso Vieira foi o que 
Revista Catarinense de Economia - RCE

APEC - Associação dos Pesquisadores em Economia Catarinense

1 은 Semestre de 2018 - www.apec.pro.br/rce

menos destinou recursos para a educação em termos relativos, a média da despesa realizada entre 1995-1998 ficou em torno de 14\%.

"Santa Catarina: Estado Vencedor" foi o plano de governo lançado pelo governador Esperidião Amin, do PPB, para o período entre 1999 e 2002. Este plano não possuía um orçamento com previsão de gastos, apenas intenções que deveriam orientar as ações do governo. Para a educação previa alterações de cunho liberal, como a implementação da autonomia financeira para as escolas para desonerar o Estado e parcerias entre as escolas e empresas privadas (HELOU FILHO, 1998). A média de gastos realizada com a função durante este governo foi também uma das mais baixas, ficando em 15,84\% das despesas totais.

No período entre 2003 e 2010 foram lançados o Plano 15 (2003-2006) e o Plano 15 II: a mudança continua (2007-2010), do governador Luiz Henrique da Silveira, do PMDB. Foram planos apenas de intenções, sem amarras orçamentárias; metas sem previsão de gastos. O Plano 15 elencava prioridades para o governo, cuja principal era a descentralização da tomada de decisões governamentais. Para a educação visava a descentralização e intensificação do processo de municipalização das escolas. Durante o primeiro governo de Luiz Henrique da Silveira, a média da despesa realizada com educação foi de $18,30 \%$. No segundo mandato, houve uma retração da participação dos gastos com a função, ficando a média em 15,74\%.

Conforme apresentado na Tabela 3, apesar das oscilações na média da despesa realizada por governo, pode-se constatar que os gastos com a função educação durante todo o período analisado corresponderam à parte significativa dos gastos totais de cada governo. Isto, portanto, faz-nos pensar que, além de o quanto os governos gastaram com educação, importanos saber a qual modelo de educação financiaram. Se fora uma educação para formação ampla do ser, mais humanista, ou uma educação restrita e instrumentalizada apenas para atender aos interesses do mercado.

\section{Despesa realizada por órgãos de governo}

$\mathrm{Na}$ análise da despesa realizada por órgãos de governo, se consideramos as médias de cada órgão em todo o período analisado, a Secretaria de Educação recebeu o maior percentual de recursos em relação a despesa realizada total, embora haja alguns períodos em que outros órgãos receberam um percentual maior que esta Secretaria. Porém, esses valores não se mantiveram no mesmo patamar por um período longo. De 1957 a 2010, a média de recursos 
Revista Catarinense de Economia - RCE

APEC - Associação dos Pesquisadores em Economia Catarinense

1은 Semestre de 2018 - www.apec.pro.br/rce

recebidos pela Secretaria de Educação em relação aos gastos totais foi de 17,90\%. Em 1956, foi destinada para a Secretaria de Educação, Saúde e Assistência Social, 21,81\% dos recursos.

A Secretaria da Fazenda recebeu o segundo maior percentual da série analisada, com média de 16,59\%. No entanto, em alguns anos, essa Secretaria recebeu montantes relativamente maiores do que a Secretaria de Educação, como aconteceu entre 1956 e 1966, 1969 e 1975, e de 2005 a 2009. Os Encargos Gerais e as Transferências aos Municípios, embora não sejam órgãos do governo, apareceram nos balanços das prestações de contas ao lado destes órgãos, durante o período 1977 a 2004. No período anterior a 1977, esses montantes foram contabilizados na conta da Secretaria da Fazenda, inflando sua participação no total de gastos. No período posterior a 2004, estes valores passaram a ser contabilizados parte na Secretaria da Fazenda e parte na de Administração.

Exatamente durante o período em que Encargos Gerais e Transferências aos Municípios aparecem separadamente nos relatórios, a participação da Secretaria da Fazenda reduziu-se bruscamente, perfazendo a média de 3,94\%. A participação dos Encargos Gerais sobre os gastos totais, no período de 1977 a 2004 girou em torno de 26,52\% e a das Transferências aos Municípios, em 13,97\%. Os Departamentos Autonômos, que aparecem nos relatórios até 1970, constituem um agregado de órgãos do governo independentes. Durante os anos de 1959 a 1963, compõem esse agregado os seguintes órgãos: Comissão de Energia Elétrica, Departamento Estadual de Estatística, Departamento Estadual de Geografia e Cartografia, Ministério Público, Polícia Militar, Departamento Estadual de Caça e Pesca, além da Secretaria Geral do POE (Plano de Obras e Equipamentos) e os gastos vinculados ao PLAMEG (Plano de Metas do Governo), conforme apresentado na Tabela 5.

Os valores vinculados ao PLAMEG, a partir de 1964, passaram a ser contabilizados dentro de um órgão próprio criado para sua execução, o Gabinete de Planejamento do Plano de Metas do Governo - GAPLAN. Os recursos vinculados ao PLAMEG apareceram nos relatórios de Prestação de Contas até 1970. Na Tabela 4, durante o período de 1964 a 1970, os valores vinculados ao PLAMEG foram contabilizados dentro da soma Outros, por aparecerem apenas em um curto período. A participação do PLAMEG no total de gastos durante este período foi a seguinte: em 1964, 23,11\%; em 1965, 23,25\%; em 1966, 13,41\%; em 1967, 14,47\%; em 1968, 32,86\%; em 1969, 22,35\%; e em 1970, 16,55\%. Na soma Outros, também encontravam-se contabilizados todos os demais órgãos, especialmente secretarias de governo que foram sendo criadas e extintas ao longo dos governos, permanecendo ativas por curto 
Revista Catarinense de Economia - RCE

APEC - Associação dos Pesquisadores em Economia Catarinense

1 은 Semestre de 2018 - www.apec.pro.br/rce

período de tempo e/ou que receberam uma parcela muito pequena de recursos em relação ao total da despesa. 
Revista Catarinense de Economia - RCE

APEC - Associação dos Pesquisadores em Economia Catarinense

10 Semestre de 2018 - www.apec.pro.br/rce

Tabela 4 - Participação da despesa realizada por órgãos em relação aos gastos totais do Estado de Santa Catarina (1956-2010) (em \%)

Cultura,

Sec.

Sec.

Dept. Sec. Sec. Sec. Esporte e Sec. Saúde e Segurança Transportes Encarg. Transf. a

\begin{tabular}{|c|c|c|c|c|c|c|c|c|c|c|c|c|c|c|c|}
\hline Ano & Legislativo & Judiciário & Autônomos & Admin. & Agricultura & Educação & Turismo & Fazenda & Assistência & Pública & e Obras & Gerais & Município & Outros & Total \\
\hline 1956 & 2,72 & 1,96 & 0,50 & - & 8,27 & - & - & 37,37 & - & 6,26 & 17,80 & - & - & 25,12 & 100,00 \\
\hline 1957 & 2,72 & 2,61 & 12,88 & - & 5,33 & 19,03 & - & 26,51 & 5,97 & 6,55 & 15,48 & - & - & 2,93 & 100,00 \\
\hline 1958 & 2,24 & 1,96 & 12,62 & - & 4,46 & 17,44 & - & 34,19 & 5,35 & 5,80 & 12,68 & - & - & 3,26 & 100,00 \\
\hline 1959 & 3,00 & 1,41 & 13,29 & - & 3,95 & 15,75 & - & 43,59 & 5,53 & 5,81 & 5,27 & - & - & 2,40 & 100,00 \\
\hline 1960 & 3,40 & 1,46 & 14,08 & - & 4,35 & 16,74 & - & 26,72 & 5,15 & 6,53 & 18,85 & - & - & 2,73 & 100,00 \\
\hline 1961 & 2,89 & 1,38 & 25,63 & - & 2,86 & 18,06 & - & 43,74 & 4,74 & 6,14 & 13,79 & - & - & 2,65 & 100,00 \\
\hline 1962 & 2,36 & 1,27 & 32,03 & - & 3,17 & 18,99 & - & 23,13 & 4,65 & 1,07 & 10,50 & - & - & 2,82 & 100,00 \\
\hline 1963 & 2,35 & 1,17 & 29,37 & - & 3,57 & 16,36 & - & 24,13 & 4,33 & 0,87 & 14,64 & - & - & 3,21 & 100,00 \\
\hline 1964 & 2,22 & 1,26 & 6,27 & - & 2,72 & 17,48 & - & 24,40 & 4,45 & 0,97 & 13,02 & - & - & 27,21 & 100,00 \\
\hline 1965 & 2,53 & 1,29 & 6,03 & - & 2,54 & 17,24 & - & 25,08 & 4,53 & 1,00 & 12,64 & - & - & 27,10 & 100,00 \\
\hline 1966 & 2,09 & 1,54 & 5,68 & - & 2,24 & 25,90 & - & 26,63 & 4,90 & 1,19 & 12,88 & - & - & 16,96 & 100,00 \\
\hline 1967 & 3,25 & 1,96 & 15,45 & - & 2,58 & 27,66 & - & 22,56 & 5,00 & 1,34 & 1,75 & - & - & 18,45 & 100,00 \\
\hline 1968 & 2,35 & 1,72 & 13,53 & - & 1,69 & 20,51 & - & 18,65 & 3,70 & 0,92 & 1,25 & - & - & 35,68 & 100,00 \\
\hline 1969 & 1,81 & 2,01 & 15,75 & - & 2,15 & 21,20 & - & 25,79 & 3,26 & 1,19 & 1,21 & - & - & 25,62 & 100,00 \\
\hline 1970 & 1,61 & 1,56 & 8,73 & - & 1,83 & 20,69 & - & 36,97 & 2,98 & 5,61 & 0,90 & - & - & 19,12 & 100,00 \\
\hline 1973 & 1,40 & 1,95 & - & 0,32 & 2,70 & 21,16 & - & 38,59 & 4,15 & 5,32 & 14,03 & - & - & 10,39 & 100,00 \\
\hline 1974 & 1,39 & 2,04 & - & 0,21 & 2,40 & 19,10 & - & 37,74 & 3,28 & 5,26 & 18,06 & - & - & 10,54 & 100,00 \\
\hline 1975 & 1,66 & 1,98 & - & 0,17 & 1,82 & 18,31 & - & 44,61 & 2,53 & 4,93 & 16,27 & - & - & 7,71 & 100,00 \\
\hline 1977 & 1,60 & 1,77 & - & 0,64 & 1,93 & 17,13 & - & 6,98 & 3,63 & 5,12 & 21,06 & 23,09 & 13,04 & 4,01 & 100,00 \\
\hline 1979 & 1,64 & 1,58 & - & 0,72 & 1,87 & 15,42 & 0,75 & 5,72 & 5,47 & 4,69 & 13,45 & 31,94 & 13,03 & 3,72 & 100,00 \\
\hline 1980 & 1,44 & 1,39 & - & 0,23 & 2,51 & 15,54 & 0,88 & 5,27 & 5,39 & 4,39 & 15,16 & 28,89 & 13,18 & 5,73 & 100,00 \\
\hline 1981 & 1,50 & 1,93 & - & 0,34 & 3,00 & 20,70 & 1,16 & 4,48 & 5,51 & 5,06 & 20,16 & 29,93 & 0,22 & 6,01 & 100,00 \\
\hline 1982 & 1,39 & 1,75 & - & 0,27 & 2,86 & 16,25 & 1,14 & 4,11 & 4,40 & 4,22 & 15,91 & 42,25 & - & 5,45 & 100,00 \\
\hline 1983 & 2,11 & 3,51 & - & 0,27 & 4,09 & 17,74 & 0,68 & 3,00 & 4,26 & 5,54 & 12,79 & 27,88 & 12,70 & 5,42 & 100,00 \\
\hline 1984 & 1,95 & 2,76 & - & 0,35 & 6,36 & 17,90 & 0,77 & 2,99 & 4,32 & 5,54 & 10,77 & 27,99 & 13,18 & 5,13 & 100,00 \\
\hline 1985 & 2,10 & 2,84 & - & 0,34 & 5,12 & 19,13 & 0,85 & 3,35 & 4,21 & 5,76 & 11,16 & 26,43 & 12,82 & 5,89 & 100,00 \\
\hline 1986 & 2,11 & 2,96 & - & 0,31 & 4,34 & 18,52 & 0,72 & 2,87 & 4,46 & 5,66 & 9,84 & 29,88 & 13,33 & 4,99 & 100,00 \\
\hline 1987 & 2,02 & 2,79 & - & 0,36 & 3,85 & 20,86 & 0,59 & 3,17 & 4,33 & 5,91 & 6,56 & 31,27 & 13,31 & 5,00 & 100,00 \\
\hline 1988 & 2,03 & 2,06 & - & 0,67 & 4,64 & 17,56 & 0,41 & 3,04 & 9,40 & 6,64 & 5,27 & 32,07 & 10,30 & 5,90 & 100,00 \\
\hline 1989 & 2,16 & 2,39 & - & 0,60 & 3,42 & 17,39 & 0,32 & 3,51 & 5,02 & 7,67 & 4,78 & 35,42 & 11,92 & 5,40 & 100,00 \\
\hline 1990 & 2,02 & 2,83 & - & 0,49 & 3,02 & 17,53 & 0,30 & 2,89 & 5,01 & 8,69 & 5,06 & 31,12 & 16,70 & 4,34 & 100,00 \\
\hline 1991 & 1,88 & 3,10 & - & 0,53 & 4,82 & 16,85 & 0,14 & 2,61 & 4,92 & 7,62 & 5,86 & 27,86 & 18,79 & 5,01 & 100,00 \\
\hline 1992 & 2,31 & 3,67 & - & - & 5,09 & 15,28 & - & 2,83 & 3,77 & 6,84 & 8,08 & 31,41 & 16,38 & 4,36 & 100,00 \\
\hline
\end{tabular}


Revista Catarinense de Economia - RCE

APEC - Associação dos Pesquisadores em Economia Catarinense

10 Semestre de 2018 - www.apec.pro.br/rce

\begin{tabular}{|c|c|c|c|c|c|c|c|c|c|c|c|c|c|c|c|}
\hline 1993 & 2,48 & 4,79 & - & - & 6,78 & 16,46 & - & 2,98 & 4,13 & 7,84 & 10,70 & 20,99 & 18,12 & 4,72 & 100,00 \\
\hline 1994 & 2,28 & 3,12 & - & - & 4,67 & 18,48 & - & 5,28 & 5,03 & 7,20 & 10,61 & 22,85 & 16,08 & 4,40 & 100,00 \\
\hline 1995 & 2,78 & 4,34 & - & 0,29 & 5,48 & 19,50 & - & 6,16 & 5,32 & 8,91 & 5,06 & 16,31 & 18,99 & 6,86 & 100,00 \\
\hline 1999 & 3,37 & 5,10 & - & 0,50 & 4,70 & 19,52 & - & 4,64 & 4,63 & 10,48 & 0,16 & 19,33 & 22,10 & 5,47 & 100,00 \\
\hline 2003 & 2,87 & 5,25 & - & 5,60 & 3,83 & 18,43 & 0,38 & 3,43 & 10,45 & 10,94 & 5,44 & 10,22 & 18,97 & 4,17 & 100,00 \\
\hline 2004 & 3,03 & 5,28 & - & 5,87 & 3,53 & 16,75 & 0,50 & 3,40 & 10,85 & 11,10 & 4,16 & 9,88 & 20,13 & 5,54 & 100,00 \\
\hline 2005 & 2,91 & 5,66 & - & 8,23 & 3,77 & 14,35 & 0,52 & 32,47 & 9,97 & 10,99 & 4,10 & - & - & 7,04 & 100,00 \\
\hline 2006 & 3,71 & 6,68 & - & 20,54 & 4,31 & 13,15 & 1,26 & 14,99 & 11,49 & 11,36 & 3,81 & - & - & 8,71 & 100,00 \\
\hline 2007 & 3,74 & 6,87 & - & 19,63 & 3,80 & 14,08 & 1,60 & 14,23 & 11,99 & 11,22 & 3,57 & - & - & 9,27 & 100,00 \\
\hline 2008 & 3,68 & 7,21 & - & 17,94 & 3,59 & 14,10 & 1,65 & 15,42 & 12,44 & 10,56 & 2,66 & - & - & 10,77 & 100,00 \\
\hline 2009 & 3,85 & 7,49 & - & 18,11 & 3,23 & 13,33 & 1,39 & 13,73 & 12,62 & 11,37 & 4,38 & - & - & 10,50 & 100,00 \\
\hline 2010 & 3,93 & 7,63 & - & 19,15 & 3,14 & 13,95 & 1,21 & 12,82 & 12,33 & 11,45 & 3,03 & - & - & 11,38 & 100,00 \\
\hline
\end{tabular}

Fonte: IBGE, 1960, 1961-1963, 1966, 1968-1984; SANTA CATARINA, 1957-1960, 1962, 1964-1971, 1974-1976, 1978, 1980-1981, 1984-1995, 1996b, 2000b, 2004-2011.

(Elaborado pela autora)

Tabela 5 - Decomposição do gasto por Departamentos Autônomos (1959-1963)

\begin{tabular}{|c|c|c|c|c|c|}
\hline Órgão & 1959 & 1960 & 1961 & 1962 & 1963 \\
\hline Comissão de Energia Elétrica & 0,95 & 0,95 & 0,65 & 0,74 & 1,10 \\
\hline Departamento Estadual de Estatística & 0,33 & 0,35 & 0,32 & 0,27 & 0,17 \\
\hline Departamento Estadual de Geografia e Cartografia & 0,14 & 0,13 & 0,11 & 0,11 & 0,08 \\
\hline Ministério Público & 0,56 & 0,60 & 0,62 & 0,54 & 0,50 \\
\hline Polícia Militar & - & - & - & 4,79 & 4,29 \\
\hline PLAMEG & - & - & 21,89 & 25,42 & 21,71 \\
\hline Departamento Estadual de Caça e Pesca & - & - & - & - & 0,08 \\
\hline Secretaria Geral do POE & 11,11 & 11,86 & 1,85 & - & - \\
\hline Outros & 0,20 & 0,19 & 0,19 & 0,16 & 1,44 \\
\hline Total Departamentos Autônomos & 13,29 & 14,08 & 25,63 & 32,03 & 29,37 \\
\hline
\end{tabular}

Fonte: SANTA CATARINA, 1964. 
A Secretaria de Transportes e Obras recebeu ao longo do período, em média, 9,44\% do total da despesa realizada, atingindo maiores níveis de participação nas décadas de 1950 e 1970. A Secretaria de Segurança Pública recebeu em média 6,21\% ao longo de todo o período, no entanto, observa-se um movimento de expansão da participação deste órgão no total das despesas ao longo dos anos, chegando aos anos 2000 com uma média de participação de $11 \%$. Saúde e Assistência Social, que na maior parte do período estiveram agregadas em uma única secretaria receberam em média $5,77 \%$ dos recursos totais, observando um expressivo crescimento desta participação também na década de 2000, mais especificamente, a partir de 2003. A Secretaria de Agricultura manteve ao longo do período uma média de $3,70 \%$, com poucas oscilações.

O Poder Judiciário, com média de 3,05\%, seguiu uma trajetória de gastos crescentes e foi aumentando sua participação nos gastos totais ao longo dos anos. Com média de 1,5\% desde a década de 1950 até o final dos 1960, alcançou crescimento expressivo a partir da década de 1980 e atingindo 7,63\% dos gastos totais do estado ao final dos anos 2000 . O Poder Legislativo, cuja média geral foi de 2,42\%, já nas décadas de 1950 e 1960 participava com cerca de 2,5\% dos gastos totais, aumentando sua participação a partir da década de 1980 e seguindo numa trajetória crescente até o final dos anos 2000. Cultura, Esporte e Turismo, que em boa parte do período analisado foram agregados na mesma Secretaria, perfazem uma média de $0,82 \%$ do total das despesas realizadas, a menor em relação aos demais órgãos analisados.

Pode-se afirmar, portanto, que a Secretaria de Educação foi um dos órgãos que mais recebeu recursos ao longo da série estudada. Analisaremos então, a decomposição do gasto desta Secretaria segundo as categorias econômicas, abrindo os dados por despesas correntes e despesas de capital (Gráfico 4). Constata-se, neste período, que o maior percentual de gastos da Secretaria de Educação é com despesas correntes ao longo de todo o período, entretanto, há períodos em que reduziu a sua participação, aumentando os gastos com despesas de capital. Os anos em que há maior dispêndio com despesas de capital foram 1969 a 1979, e de 1984 a 1987. Em 1977, a despesa de capital atingiu $14,21 \%$ do total, o maior percentual em toda a série analisada.

Ao analisarmos a composição da despesa segundo as categorias econômicas, temos as contas de Custeio e de Transferências Correntes, que compõem as Despesas Correntes; e Investimentos, Inversões Financeiras e Transferências de Capital, que compõem as Despesas de Capital. As Despesas Correntes são aquelas realizadas com a manutenção dos 
equipamentos e com o funcionamento dos órgãos, o que inclui o gasto com pessoal e encargos, materiais de consumo, etc. As Despesas de Capital são aquelas realizadas com o propósito de formar e/ou adquirir ativos reais, abrangendo, entre outras ações, o planejamento e a execução de obras, a compra de instalações, equipamentos, etc.

Gráfico 4 - Participação na despesa realizada da Secretaria de Educação, segundo despesas correntes e de capital (1964-2010) (em \%)

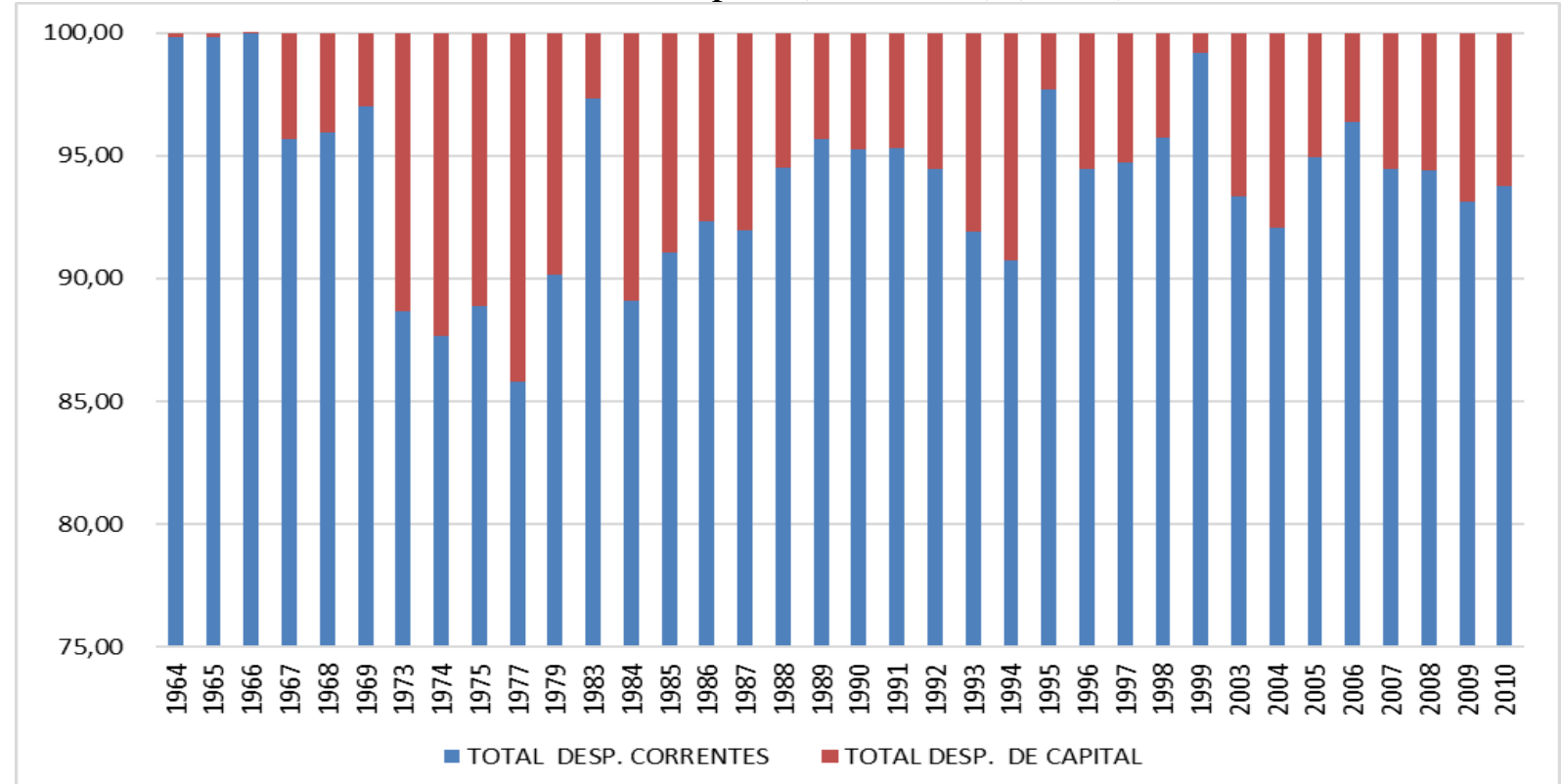

Fonte: SANTA CATARINA, 1965-1970, 1974-1976, 1978, 1980, 1984-1995, 1996b, 1997-1999, 2000b, 20042011. (Elaborado pela autora)

O gasto com Custeio foi o mais elevado em todo o período, mantendo-se em torno da média 73,60\%. Na década de 1990, ocorreu uma queda relativa da despesa com custeio, e um aumento do gasto com transferências correntes, quando este atinge o percentual de 43,31\%. Os investimentos mantiveram a média $4,25 \%$, chegando a alcançar a participação de $12,21 \%$ em 1974. Quanto aos investimentos, há uma ressalva. Parte do valor empregado em novas construções e obras da educação, pode ter sido contabilizado na Secretaria de Transportes e Obras, ficando reduzido o percentual contabilizado na conta da Secretaria de Educação. As Transferências de Capital se manteve em torno de 1,77\% das despesas totais da SED, alcançando um volume maior apenas em meados da década de 1970.

\section{Despesa realizada de acordo com as vinculações constitucionais para} Manutenção e Desenvolvimento do Ensino 
Ao longo da história, na elaboração das diversas constituições nacionais e estaduais houveram sucessivas vinculações e desvinculações de recursos provenientes de impostos para a manutenção e desenvolvimento do ensino, nas três esferas de governo. A vinculação de recursos para Manutenção e Desenvolvimento do Ensino (MDE) foi instituída pela primeira vez na Constituição de 1934, durante o governo de Getúlio Vargas. Em 1937, com o Estado Novo e a criação de uma nova constituição, foi omitida. Em 1946, após a deposição de Getúlio Vargas do poder, a nova constituição foi promulgada instituindo a obrigatoriedade de vinculação de recursos para Manutenção e Desenvolvimento do Ensino, em nível federal, estadual e municipal. Em 1967, em função do golpe civil-militar de 1964, foi promulgada uma nova constituição, que omitiu novamente a vinculação de recursos para a educação. Ainda durante o período da ditadura militar, a Emenda Constitucional $n^{\circ} 1$, de 17 de outubro de 1969 instituiu a vinculação de 20\% da receita municipal para o ensino primário.

Somente em 1983, com a Emenda à Constituição Federal n ${ }^{\circ}$ 24, de 01 de dezembro de 1983, conhecida também como Emenda João Calmon, e regulamentada pela Lei $\mathrm{n}^{\circ} 7.348$, de 24 de julho de 1985, voltou-se a vincular um percentual da receita de impostos para Manutenção e Desenvolvimento do Ensino (vinculação obrigatória de 13\% da arrecadação de impostos para a União, e de $25 \%$ para os Estados, o Distrito Federal e os Municípios). A Constituição Federal promulgada em 05 de outubro de 1988, manteve a vinculação de recursos para a Manutenção e Desenvolvimento do Ensino, alterando apenas o percentual mínimo a ser aplicado pela União, de $13 \%$ para $18 \%$ da receita resultante de impostos.

No entanto, nos relatórios de prestação de contas do governo do Estado analisados, não encontramos menção de um tópico específico que tratasse do percentual de despesa realizada para Manutenção e Desenvolvimento do Ensino, segundo as vinculações constitucionais.

Gráfico 5 - Percentual gasto com Manutenção e Desenvolvimento do Ensino, segundo vinculações constitucionais (1987-2010) (em \%)

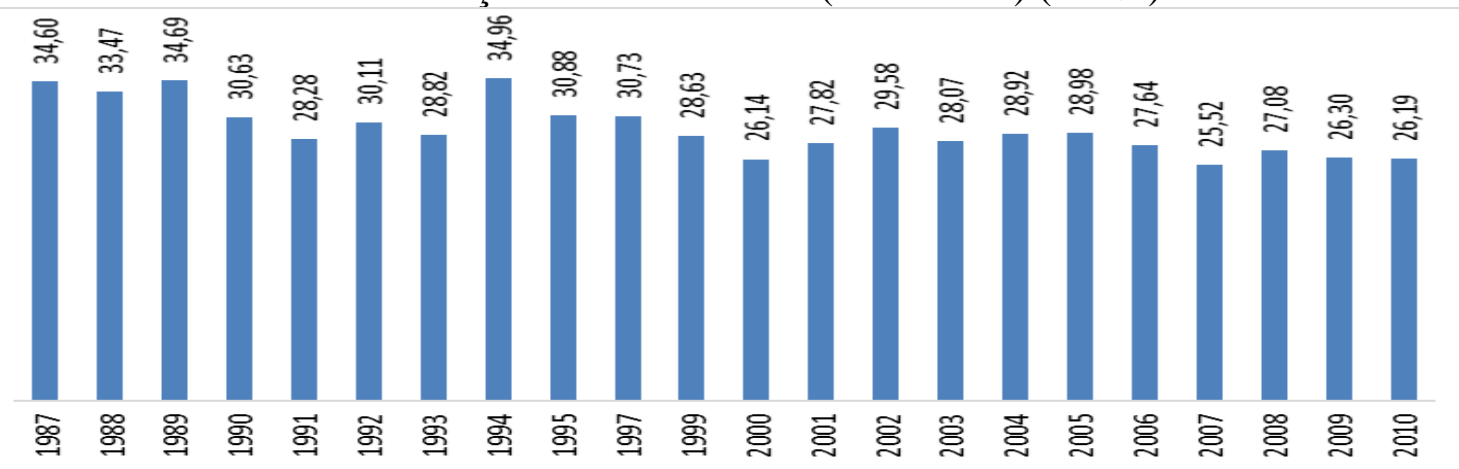

Fonte: SANTA CATARINA, 1988-1995, 1996b, 1998, 2000b, 2001-2011. (Elaborado pela autora) 
O relatório de prestação de contas de 1987 foi o primeiro a apresentar informações sobre a despesa realizada com Manutenção e Desenvolvimento do Ensino, segundo as vinculações constitucionais da Emenda Constitucional nº 24, de 1983 (regulamentada pela Lei n ${ }^{\circ}$ 7.348, de 1985) e da Emenda à Constituição do Estado de Santa Catarina no 23, de 1984. Em 1987, o percentual da receita de impostos aplicado na manutenção e desenvolvimento do ensino pelo estado catarinense foi de 34,60\%, acima do mínimo requerido pela legislação. Durante o período de 1987 até 2010, em que constam os dados do percentual aplicado na Manutenção e Desenvolvimento do Ensino pelo governo estadual nos relatórios de prestação de contas, o percentual apresentado superou o mínimo exigido constitucionalmente, chegando a $34,96 \%$ em 1994. O menor percentual aplicado foi $25,52 \%$, no ano de 2007 , no entanto, ainda cumprindo a exigência constitucional. A média do percentual aplicado em todo o período apresentado foi de $29,61 \%$.

Todavia, é importante mencionar que, apesar de serem estes os dados apresentados pelos governadores do Estado nos relatórios de prestações de contas, existem ressalvas feitas pelos analistas do Tribunal de Contas do Estado quanto às formas de cálculo para se chegar a esses percentuais. Estas não estariam de acordo com o que prevê a legislação, quando, por exemplo, há a inclusão da despesa realizada com pessoal inativo no montante, levando ao entendimento de que possa haver distorções no cálculo apresentado pelo governo, para que se faça cumprir o percentual mínimo exigido constitucionalmente.

\section{Considerações finais}

Nos propomos nesta pesquisa a apresentar e analisar a trajetória de gastos do governo do Estado de Santa Catarina com educação entre 1955 e 2010, com o intuito de demostrar que ao longo das últimas décadas o Estado tem gastado parte expressiva da sua despesa total com esta função, e problematizar o discurso presente na sociedade de que o Estado não "investe" em educação. Por meio da pesquisa nos relatórios de Prestação de Contas do Governo do Estado de Santa Catarina e dos Anuários Estatísticos do IBGE, verificou-se que historicamente o Estado de Santa Catarina tem destinado parte expressiva dos seus gastos para a educação. A média de gastos do governo estadual catarinense com a função no período analisado ficou em torno de $18 \%$ do total de gastos realizados, chegando em alguns períodos a compreender até $26 \%$ da despesa total. $\mathrm{Na}$ análise dos gastos por órgãos de governo, se 
Revista Catarinense de Economia - RCE

APEC - Associação dos Pesquisadores em Economia Catarinense

1을 Semestre de 2018 - www.apec.pro.br/rce

consideramos as médias de cada órgão em todo o período analisado, a Secretaria de Educação também foi o órgão que recebeu o maior percentual de recursos em relação a despesa realizada total. Embora haja alguns períodos em que outros órgãos tenham recebido percentuais maiores que esta Secretaria, os valores não se mantiveram no mesmo patamar por um período longo, como foi o caso desta Secretaria. Isso demonstra a permanência do elevado gasto com Educação, desconstruindo a falácia de que a educação fora colocada em segundo plano em termos de recursos governamentais.

Com isso, não queremos dizer que não é preciso gastar parte expressiva dos orçamentos nas três esfera dos governos com a educação, mas que apesar de o estado catarinense gastar parte expressiva do seu orçamento com esta função, os problemas educacionais e socioeconômicos têm persistido ao longo tempo. Tais problemas invalidam o discurso presente na sociedade brasileira que coloca a educação como panaceia, ao afirmar que somente o aumento do gasto educacional poderia promover o desenvolvimento social e econômico. Afirmamos, com Furtado (2004), que dispor de recursos para investir não é condição suficiente para promover o desenvolvimento. É necessário compreender, portanto, que a expansão do gasto público em educação é apenas um dos elementos que podem contribuir para o desenvolvimento educacional e socioeconômico de uma sociedade, e que sua contribuição é limitada. Há de se considerar o desenvolvimento socioeconômico como uma totalidade que envolve o bom desempenho de um conjunto variado de setores da sociedade e da economia (trabalho, renda, infraestrutura, transporte, saúde, saneamento básico, etc.) que poderão, em um processo dinâmico e dialético, levar ao desenvolvimento. E, para além do volume de gastos despendidos na educação pública, é preciso considerar de que forma e em que tipo de educação esses recursos foram empregados, ou seja, a que modelo educacional eles financiaram.

Nesse sentido, a análise detalhada dos relatórios de prestação de contas, alinhada a análise das diretrizes educacionais presentes nos planos de desenvolvimento dos governos tornou-se fundamental para a compreensão das concepções educacionais presentes em cada época. Entendemos que as leis, diretrizes e planos educacionais, assim como os planos de governo catarinenses, foram elaborados dentro de um contexto maior, orientado pelo modelo de desenvolvimento incorporado pelo Brasil e pela concepção política dominante em cada época, não sem resistências, contradições e fissuras, ao mesmo tempo em que seus conteúdos também influenciaram a criação de novas concepções sócio-educacionais. Buscando compreender as tensões e permanências em torno dessas concepções, percebeu-se, ao longo 
Revista Catarinense de Economia - RCE

APEC - Associação dos Pesquisadores em Economia Catarinense

1 o Semestre de 2018 - www.apec.pro.br/rce

da análise dos documentos, que há uma crescente instrumentalização da educação para atender as demandas empresariais e do mercado de trabalho, em detrimento de uma concepção humanista de educação. Na análise dos planos, apesar do alargamento das frentes de atuação em consonância com as diretrizes internacionais, os objetivos da educação catarinense permaneceram conservadores, com a predominância em atender as necessidades do mercado.

\section{Referências}

AURAS, Gladys Mary Teive. Modernização econômica e formação do professor em Santa Catarina. Florianópolis: Editora da UFSC, 1998.

BORNHAUSEN, Jorge Konder. Plano de Ação. Florianópolis, 1979.

BORNHAUSEN, Irineu. Plano de Obras e Equipamentos. Florianópolis, 1955.

CAMPOS, Pedro Ivo. Rumo à Nova Sociedade Catarinense. Florianópolis, 1986.

FURTADO, Celso. Os Desafios da Nova Geração. Revista de Economia Política, vol. 24, nº 4, 2004.

HELOU FILHO, Esperidião Amin. Cartas dos Catarinenses. Florianópolis, 1982.

HELOU FILHO, Esperidião Amin. Santa Catarina Estado Vencedor. Florianópolis, 1998.

IBGE - INSTITUTO BRASILEIRO DE GEOGRAFIA E ESTATÍSTICA. Anuário

Estatístico do Brasil. Rio de Janeiro: IBGE, 1946-2010. Disponível em:

$<$ https://biblioteca.ibge.gov.br/index.php/biblioteca-catalogo?view=detalhes\&id=720>.

Acesso em: 07 abr. 2015.

KLEINÜBING, Vilson. Plano SIM: para viver melhor em Santa Catarina. Florianópolis, 1990.

KONDER REIS. Antonio Carlos. Plano de Governo 1975-1979. Florianópolis, 1975.

SALLES, Colombo Machado. Projeto Catarinense de Desenvolvimento. Florianópolis, 1971.

SANTA CATARINA. Lei Estadual 2.772 de 21 de julho de 1961. Assembleia Legislativa do Estado de Santa Catarina, 1961. Disponível em <http://www.alesc.sc.gov.br> Acesso em: 02 maio 2015.

SANTA CATARINA. Secretaria da Fazenda. Prestação de Contas. Florianópolis, 19571960. Microfilme.

SANTA CATARINA. Secretaria da Fazenda. Prestação de Contas. Florianópolis, 1962. Microfilme.

SANTA CATARINA. Secretaria da Fazenda. Prestação de Contas. Florianópolis, 19641971.

SANTA CATARINA. Secretaria da Fazenda. Prestação de Contas. Florianópolis, 19741976. Microfilme.

SANTA CATARINA. Secretaria da Fazenda. Prestação de Contas. Florianópolis, 1978. 
SANTA CATARINA. Secretaria da Fazenda. Prestação de Contas. Florianópolis, 1980. Microfilme.

SANTA CATARINA. Gabinete do Governador. Prestação de Contas. Florianópolis, 1981.

SANTA CATARINA. Secretaria de Estado da Fazenda. Prestação de Contas. Florianópolis, 1984-1995.

SANTA CATARINA. Secretaria de Estado da Fazenda. Balanço Geral do Exercício. Florianópolis, 1996a.

SANTA CATARINA. Tribunal de Contas. Relatório e Parecer Prévio Sobre a Prestação de Contas. Florianópolis, 1996b.

SANTA CATARINA. Secretaria de Estado da Fazenda. Balanço Geral do Exercício. Florianópolis, 1997-1999.

SANTA CATARINA. Secretaria de Estado da Fazenda. Balanço Geral do Exercício. Florianópolis, 2000a.

SANTA CATARINA. Tribunal de Contas. Parecer Prévio Sobre as Contas Prestadas pelo Governador do Estado. Florianópolis, 2000b.

SANTA CATARINA. Tribunal de Contas. Parecer Prévio Sobre as Contas Prestadas pelo Governador do Estado. Florianópolis, 2001-2003.

SANTA CATARINA. Secretaria de Estado da Fazenda. Balanço Geral do Estado. 20042011. Disponível em: <http://www.sef.sc.gov.br/transparencia/relatorio/8>. Acesso em: 03 jun. 2018.

SAVIANI, Dermeval. A nova lei da educação: trajetória, limites e perspectivas. 5 ed. Campinas: Autores Associados, 1999.

SILVEIRA, Ivo. Plano de Metas do Governo II - 1966-1970. Florianópolis, 1966.

SILVEIRA, Luiz Henrique da. Plano 15. Florianópolis, 2002.

SILVEIRA, Luiz Henrique da. Plano 15 II: a Mudança Continua. Florianópolis, 2006.

VIERA, Paulo Afonso. Proposta de Governo Viva Santa Catarina. Florianópolis, 1994. 